\title{
Becoming Contextually Responsive: Taking Hold of a Shared Vision for Our Profession
}

\author{
Kirsty van Stormbroek. BSc.OT (UCT); MSc.OT (UCT). http://orcid.org/0000-0003-4890-5063 \\ Lecturer, Department of Occupational Therapy, School of Therapeutic Sciences, Faculty of Health Sciences, University of the \\ Witwatersrand, Johannesburg.
}

Tania Rauch van der Merwe. B.OT; MSc. OT; PhD. http://orcid.org/0000-0002-575 I-2707

Senior Lecturer, Department of Occupational Therapy, School of Therapeutic Sciences, Faculty of Health Sciences, University of the Witwatersrand.

Equitable access to life-giving occupational participation lies at the centre of occupational therapy's mission and is pivotal to development in South Africa. Contextually responsive education, research, policy and practice are a means of achieving this. This, however, necessitates knowing how to be or become contextually responsive as individuals and as a profession. It also necessitates partnership between our 'feet on the ground' practitioners and 'head in the cloud' academics - a productive collision of reality and possibility. This commentary explores what it means to be contextually responsive, whether it's possible for practitioners and scholars to pursue this together, and poses recommendations for finding each other in the journey of becoming.

\section{INTRODUCTION}

We read with excitement the call for contributions to this Special Edition and the opportunity it presents: advancing our understanding of human occupation and the potential for societal impact. Our profession is being called to contextual responsiveness. And how could we not respond in a year in which floods, fires, violent protests, and a global pandemic have further exposed our country's systemic weaknesses? But are you, like us, looking for a 'plain-language summary' for "contextually responsive"? Do you instinctively agree to the idea of "responsiveness", eager and appropriately resolute, while at the same time hearing your more pragmatic mind asking, "But what does it actually mean?" And possibly your conscience checking if you are really willing to engage with what it may mean, particularly in COVID-19-times which continue to challenge our adaptability and capacity for change. Might it ask us to humbly enter into the lived realities and stories of individuals, communities and cultures very different from our own? Might it ask us to honestly reflect on how we have been socially advantaged while others have been made to accept disadvantage? Or, with courage, to face our disadvantage, exclusion and pain, while humbly and firmly rejecting the very real pressure to believe that we are less than or, the other. Might it ask us to relate to others on the level ground of our shared humanity, dignity and worth rather than operating out of the comfort, security and confidence derived from our social identities? Might it require us to welcome and embrace diversity, and be enriched by it, rather than act out a feeling threatened by difference? If you can relate to some of these "wonderings", then perhaps you also want to move beyond the rhetoric and unpack what it means to be 'contextually responsive', and decide: is it imperative? Are we willing? Am I wiling?

The call suggests that our profession may not be contextually responsive, that it may have a way to go or, at the very least, is in need of critically reflecting on its responsiveness. It suggests that we may be falling short of our potential as a profession in contributing to the development of our country. Perhaps, knowing this instinctively, we are quick to agree with the need to become responsive to our context. However, if we don't understand what we're falling short of, and what our potential is, then our talk of contextual responsiveness remains the exchange of professional pleasantries. If we are to leverage a synergistic strength, as a profession of around 6000 occupational therapists, technicians and assistants, is it not essential for us all to harness our collective strengths as practitioners and academics?

In addition, it seems prudent to ask: is it possible for our practitioners and scholars to pursue contextual responsiveness together, given our different outlook posts: one for practice, and another for theory? Can we orientate towards being 'on the same page', speaking a shared professional language about the meaning of contextual responsiveness, and journeying toward a shared vision of contextually responsive practice? This commentary is a simple and honest contribution towards a productive fusion between what is, and what can be, and articulates an intention to not leave any of our colleagues behind in the process. It explores the questions posed above and proposes mechanisms for growth and development as a South African occupational therapy academy .

\section{A point of departure: how are we currently positioned as a profession? \\ Occupational participation is deeply embedded in context and thus all attempts to enable participation as a means to health and well-being, need to be responsive to context ${ }^{1}$. An occupational therapy profession that does not consider context when developing programmes and services, is one that will simply copy-and-paste itself from one setting to another. Although this may expedite the establishment of a service and the initial expansion of the profession, this duplication approach ignores one of the triple-strands of the profession's DNA: the context and environment. To practise in a}


contextually responsive manner means that context and environment are part and parcel of the design of therapeutic interventions, uniting reality with possibility through practical wisdom, reflection, and action. This is praxis ${ }^{2}$. It is also ethical practice. Therefore, copy-and-paste practice without integrating people's context and environment may not only be counter-intuitive to contextually responsive practise, and praxis, it may also be in essence countering our duty of upholding the ethical values of beneficence and nonmaleficence, respecting people's dignity, and ensuring distributive justice ${ }^{3}$. For these reasons, to enact praxis and ethical practise, we also need to share the will to critically engage with the often historical complexities associated with context and environment of the people that we serve, along with the historical origin of occupational therapy theory.

It has been suggested that the South African occupational therapy profession was constructed on a number of theoretical duplications, or "a hodgepodge of various models" predominantly developed for contexts vastly different to our own $n^{4: 21}$. At best, this has limited our contextual responsiveness. $\mathrm{Hammel}^{5}$ argues that the implications are far more treacherous; that transferring culturallyspecific professional assumptions and beliefs, entrenches ideologies that are disabling and threatens practice that is truly client-centred ${ }^{5}$. An example of this may be the uncritical imposition of the tenets of western individualism juxtaposed to the deeply collective nature of being human on the African continent ${ }^{6}$.

What is evident in South Africa, is that the growth of our profession has been stunted and our impact constrained. Though equipped with an understanding of the potency of occupational participation to health and well-being, we continue to operate almost solely within the health sector (with a small number of therapists working in the Departments of Basic Education and Social Development). Understanding a little of the complexity of the health system into which occupational therapy services are embedded, provides helpful context for understanding our historical contribution as a profession. South Africa's healthcare system was, and remains, characterised by extreme inequality. Factors that contributed to this inequality include apartheid policy, prior colonial rule, race and gender discrimination, high levels of violence over many centuries, migrant labour, income inequality and the destruction of family life ${ }^{7}$. Fragmentation and service in-co-ordination and duplication were common prior to 1994: fourteen separate health departments existed, and provincial responsibility was taken for the running of hospitals. In addition, 400 local authorities had health departments that were responsible for prevention and promotion services ${ }^{7,8}$. A curative, hospital-based approach was favoured with $76 \%$ of funding being allocated to hospital-based services prior to the country's first democratic election ${ }^{7}$. In 1994, the African National Congress's National Health Plan sought to use a Primary Health Care (PHC) approach to restructure and transform the health system. A National Health Authority was instituted to co-ordinate overall services with provincial health authorities operating in nine provinces. Priority was given to PHC facilities and strategies to improve services in rural and underserved areas were adopted ${ }^{9}$. Despite the latter and subsequent policies' attempt to shift the inequality, transformation has been hampered by a number of factors, including the continued skewing of resources towards the private sector and flaws within health system management ${ }^{10}$.

Against this backdrop, the majority of our occupational therapy services remain dedicated to a small minority of the population that have access to private sector care. Up-to-date statistics are limited but recent data suggests that around $80 \%$ of occupational therapists work in the private sector ${ }^{11,12}$ a sector which serves around $20 \%$ of the population ${ }^{13}$. We send our (arguably) most vulnerable colleagues (Community Service occupational therapists) to populations with the greatest health needs (rural and underserved populations). We have been slow to reinforce their efforts with mentoring and practice-support despite the urgent need for them to pioneer services that are strategic, contextually responsive, and more far-reaching. The demographic of our workforce $(63 \%$ white and $95 \%$ female ${ }^{\prime \prime}$ ) continues to poorly reflect the South African population, perpetuating barriers in care and limiting the diversity of knowledge and perspectives that hold potential for shaping more responsive theory and practice. We continue to reactively "tread water" against our quadruple burden of disease through curative and rehabilitation approaches, while our potential for being part of our country's transformation to a more equitable society remain unrealised.

In addition to some of the practice realities described above, which are common in many health care professions originating from applied science, a classic gap continues to exist between occupational therapy and occupational science theory, and the practice of the profession in South Africa. Occupational science may be perceived as highly theoretical with little translation into practice. Perhaps this gap is further sustained by the sheer respective workloads in various sectors, and lack of access for clinicians to literature and theoretical resources taken for granted by academics. We would argue that this dichotomy contributes to professional distance between practitioners and academics. We are cognisant that this generalisation is mostly supported by anecdotal evidence and the authors' own experiences within clinical, academic and clinical educator roles. However, we believe this perceived gap is important to address when taking stock of our current positioning as a profession and envisioning future directions against the backdrop of rapidly changed and changing contexts.

If highlighting features of our current positioning as a profession feels like a description of a glass-half-empty, we would ask you to see this commentary as reflections on our potential, rather than a judgement of the legitimate value of our current contribution. We would ask you to look with us for the opportunity: the opportunity to respond to contextual realities and take our place as a profession within our country's development.

\section{Context: what are we responding to?}

Before we can talk about being "responsive", we need to conceptualise what we are responding to: what do we mean by "context"? The physical context is relatively easy to see: rocky terrain that makes mobilising in a wheelchair difficult, or a three-by-three-meter home that renders a specialist paediatric wheelchair for a cerebral palsied family member an unrealistic necessity. Aspects of the virtual context may also be distinguishable: during the COVID-I 9 national lockdown, for example, the impact of the demands of the virtual aspect of context on coping and well-being, acting as both a barrier and facilitator of social participation, could be more readily perceived by occupational therapists. However, not all aspects of the context, and mechanisms of its impact on occupation and participation, are self-evident. Like UV light reveals invisible realities, we need specific illumination or lenses to distinguish other aspects of the environment.

Occupation-focused theoretical frameworks greatly assist with this, making more overt aspects and impacts of the context and environment. The physical, social, cultural, institutional, temporal and economic elements of the context or environment ${ }^{14-17}$ are 
typically highlighted by occupational therapy theory. More recent occupational therapy conceptual frameworks have highlighted the importance of geopolitical elements of the environment ${ }^{18}$. Intentionally superimposing these models onto our analysis of clients' occupational participation can be invaluable in understanding the enabling and disabling forces of the context and environment and developing interventions built on this understanding. With the medical model having exerted a strong historical influence in the shaping of our profession in South Africa ${ }^{4}$, we are adept at identifying the internal capacities of individuals contributing to participation limitations but often require more critical theoretical lenses to distinguish powerful influences external to the person.

We cannot, however, apply these theoretical lenses indiscriminately but need to critique their suitability for our context. For example, we would question why none of our conceptual frameworks include the spiritual environment? Although the person is acknowledged as a spiritual being by some conceptual frameworks ${ }^{17}$, the spiritual context and environment, central to many worldviews, needs to be conceptualised. Beyond an evaluation of the conceptual frameworks themselves, $\mathrm{Hammel}^{5}$ contends that an essential aspect of our critique should also involve evaluating the "ideological and structural contexts" $5: 23$ of our professional concepts and research. Essentially this speaks to interrogating the philosophical and epistemological assumptions on which our theories are built to evaluate their appropriateness, or responsiveness, for South African practice contexts.

Additionally, if we are to substantially extend our contribution as a profession through population-based interventions, our understanding of contextual shapers of participation needs to be developed. Although not an occupational therapy-specific framework, the Social Determinants of Health (SDOH) provides a very helpful lens to analyse the "non-medical factors", or "the conditions in which people are born, grow (develop), work, live, and age, and the wider set of forces and systems shaping the conditions of daily life" 19 that impact on the health outcomes of populations. Some examples of the SDOH include education, food security, employment, community safety, gender, social status and transportation, to name but a few. The diversity of factors demonstrates why our healthcare policy calls for intersectoral action and collaboration in improving health outcomes. For some of the factors, some of our profession's contribution is relatively obvious. However, we may need help understanding the "wider set of forces and systems shaping the conditions of life"19 and how occupational therapists can position themselves to address this.

Applying occupational justice theory, the Participatory Occupational Justice Framework (POJF) ${ }^{20}$ can guide us in uncovering these "forces and systems". In considering the local practice and systems context, as well as the political, socio-cultural and economic contexts that exert influence at a global, regional and national level, this Framework provides guidance in both identifying and addressing occupational injustice. Importantly, this framework helps us become aware of the influence that power relations exercise on occupation $^{20}$. Having pioneered practice in South Africa built on this awareness, Galvaan and Peters ${ }^{21}$ have developed the Occupation-based Community Development (ObCD) Framework. This framework uses a participatory approach, along with occupational science, to address community development, social inclusion, human rights and occupational justice. Engaging with this model and examples of how our colleagues have applied and developed occupational science theory in their practice can greatly expand our vision of occupational therapy's contribution in South Africa.
These concepts and theoretical frameworks in occupational therapy guide us in being able to identify, recognise and integrate the many elements of complexity and systems, toward honouring the foundation of the profession: the intrinsic relationship between context, occupation, health and well-being ${ }^{22}$. Why is it then that we need to pose these reflexive questions: Why are we not responsive in our work? Are we, as an occupational therapy profession, responding to the multi-layered context in which our profession is suspended? Are we responding to the contexts in which our clients, both individual and collective, participate? Or do our inevitable subjective worldviews and subjective realities press us to extract and understand only samples of our clients and their occupations, largely dissected from their environment? Perhaps, unwittingly, we have succumbed to the eroding global discourse of neoliberalism, during which basic human rights such as health, education, dignified ageing, and well-being are distortedly converted to market-related values of possible usefulness and personal 'capital', pushing the poor and vulnerable further into the long shadows of marginalisation ${ }^{23}$. Neoliberalism is also often undergirded by 'possessive individualism' where the individual is the owner of his/her space and ways of thinking, being and doing, assuming a freedom that is exempt from interdependence with others and the environment; a freedom that at once, too serves as a form of possession ${ }^{24}$. Perhaps the enclaves of neoliberalism and possessive individualism hinder our ability to maintain a 360-degree gaze on the grid of holism the very foundation of our theories, and an essential gaze to be contextually responsive.

Local evidence would suggest that we are only beginning to appreciate the way in which occupations of South African populations are deeply embedded in, or bounded by, the social and historical context $\mathrm{t}^{25}$. Socioeconomic and political factors of the past continue to exert a moulding force on the current occupational choices of clients and communities ${ }^{25}$. Hence, in the present we have witnessed in full force the accentuation of inequalities along the usual fault lines of race, gender, and socio-economic standing. For example, while some South Africans can expect to engage in satisfying, stimulating, safe and well-remunerated employment, others are expected to be grateful for any form of employment and accept working conditions that undermine human dignity. And we will continue to skirt around these inequalities as a profession if we fail to use the potency of our profession to affirm the dignity and worth of all citizens through access to health-giving occupations. We need to ask ourselves what insights have we garnered, and what foresight we need, to strike the balance anew: between remaining relevant as a health care profession, while addressing the $\mathrm{SDOH}$ as a critical area for occupational therapy intervention ${ }^{26}$.

\section{Responsiveness: what does this mean?}

Critically engaging with theoretical concepts and frameworks holds great potential for expanding our vision for our current practice and for new avenues of contribution. But to carefully pursue translating this engagement into prudent action, we must also consider the quality or posture of responsiveness. Responsiveness, within human biology, refers to an organism's ability to sense a stimulus or detect changes within its environment (internal or external), and to respond appropriately ${ }^{27}$. If we draw on this definition, how do we ensure that we develop this "ability to sense...and respond" judiciously to the contexts and environments in which our clients (individual and collective) and our profession are suspended? We would like to explore some interrelated elements that we believe are critical to nurturing a responsive disposition. 
Firstly cultivating a growing awareness of the influence that power relations have on occupation ${ }^{20}$ is essential to responsiveness. An ability to perceive this and exercise habitual sensitivity to the dynamics of power and dominance evident in, and entrenched by occupations, has recently been conceptualised by Ramugondo as occupational consciousness ${ }^{28}$. All environments support or hinder occupational participation ${ }^{29}$ and may create or perpetuate occupational injustice ${ }^{20}$. A consciousness of the complex, dynamic and multi-layered context of occupation helps the occupational therapist to understand 'the ecological nature of disability'29:176 and arguably the ecological nature of ability. Perhaps the capacity to readily perceive the latter will catalyse an appreciation of the former? Nevertheless, the aptitude for distinguishing power relations will equip us to position ourselves, alongside our clients to pursue participation equity, meaning occupational justice, through the 'critique and change'29:176 of disabling environments.

Additionally, engaging in critical reflection of our ourselves as individuals, our own practice and the positioning of our profession can greatly assist us in growing an awareness of power relations on occupation ${ }^{30}$. This should flow from, and assist our engagement with new theoretical perspectives. This reflection is facilitated by asking ourselves, and our colleagues, critical questions, examples of which we have posed in this commentary

Exposure to and immersion in the contexts and environments in which our clients, individual and collective, are embedded as occupational beings, is also essential to developing responsiveness. This necessitates opportunities for experiential learning, ideally through direct engagement in diverse South African contexts. An autobiographical study conducted by a South African therapist demonstrated that engagement in clients' contexts does not automatically produce responsiveness. She described a learning process of "seeing and feeling the invisible"26:4. Essential to developing this sense or awareness was the therapist engaging in critical reflection while being immersed in contexts characterised by social inequality and poverty. Prolonged exposure to clients in context along with retrospective reflection enabled the therapist to "zoom out" from her clinical view of the clients' health needs, to see their social needs, for example, that one of her clients did not (only) need a splint (sling) but had a deep need "to live a dignified life"26:4. Her realisation challenges us: Are we satisfied with preventing a painful shoulder subluxation while urgent calls are being made to address social injustice? Are we too easily satisfied with an over-reductionist focus when we are being called to serve those who wait patiently for justice? Exposure to, immersion in, reflection on, and dialogue around contexts of injustice is key to feeding a healthy sense of critical dissatisfaction with the scope of our current contributions and understanding of contextual shapers.

In addition to these elements, Richards and Galvaan ${ }^{26}$ propose that participatory approaches are essentially a means to developing contextually responsive in practice. The same researchers described the importance of therapists realising their "common humanity and shared citizenship with clients" $26: 4$. This realisation facilitates a participatory approach in which client and therapist are "equals working for change" $26: 4$ and are able to collaboratively act in response to a "shared understanding of the client's situation"26:4.

The phrase, "equals working for change"26:4 lingers as we move on to consider whether it is feasible to navigate a shared journey as a profession towards contextual responsiveness. Could this be a key to a common ground of departure for us as scholars and clinicians? Embracing the premise that when working with our clients (individual or collective), or working with one another, we are "equals working for change"26:4? In addition, might a collective "deep appreciation of humans, viewing all human beings to be of equal worth, simply because they are human and are deserving of the opportunities (or capability sets) to ensure social inclusion"21:284 create a thread of unity through our diverse work? We suggest that this belief that guided Galvaan and Peter's work on the ObCD Framework, be embraced as a compass that directs and corrects our collective efforts.

\section{Setting out together: boots in the mud and head in the clouds?}

Having explored a little of what it means to be contextually responsive, we would now like to consider the feasibility of pursuing this quality collectively - as clinicians and scholars. The experiences that come from the environments in which we work shape our thinking, as do the theoretical backgrounds that have informed our professional reasoning. They shape what we see as important in the occupational therapist's contribution and guide how we approach intervention, whether-working on the ground or at a desk with theory. Is it possible to navigate a shared journey as a profession when our perspectives are potentially very different?

To think through being contextually responsive as a profession, we would ask for a little creative licence to liken the South African occupational therapy academy to a human being - a person. This person is dressed for bad weather with a pair of sturdy, work-worn boots and is set to clear a course through a treacherous marshland. The person's legs are wading, calf-deep through mud, straining against the viscosity of the sludge, pelting rain and fierce wind. The legs' endurance-trained muscles strain and twitch with effort, preventing the person from sinking, but achieving slow progress across the seemingly endless swamp. Dark clouds swirl and promise more bad weather but these legs are resolute in out-muscling the mud. The weight of our profession's practice reality is borne by our legs - our clinicians - amidst staff shortages, maladministration, lean budgets, waiting lists and the life realities of clients and communities.

Now shift your gaze upwards, from this person's boots to their head: the person's torso is long - propelling their head high above the clouds. The sun is shining here, radiating hope for the mission. From this view, the threatening hazards of the terrain are met with promising possibilities. One possibility is to replace the mission of clearing a course through the swamp with a vision of restoring the wetland ecosystem to protect local human and animal life from frequent flooding in the area. The opportunity to reintroduce rare fish species that will support the economic activities of nearby villagers holds promise. This lofty perspective proliferates possibility. Unencumbered by sticky reality, the head, our scholars, have freedom to cast a vision and formulate a mission for the body. This freedom is considered essential to a democratic and tolerant society and enacting this liberty models for students the independent reasoning and critical thinking that is important for nurturing active and responsible citizenship ${ }^{31}$. This position and perspective 'above the clouds', is not, however, without its own resistance from the 'elements'. Training occupational therapists while holding the tension between our professional 'reality' and 'possibility' is challenging. The rapidly changing higher education landscape leaves little space for apathy or distraction, to 'just enjoy the sun'. Keeping a steady focus on the production of contextually responsive practitioners while competently responding to the press for technological advancement, research productivity and generation of departmental income requires agile and innovative adaptation.

This analogy, though somewhat embellished and admittedly 
limiting in many ways, conveys the potential challenge of navigating a shared journey as practitioners and scholars when our lived experience of the profession may be very different. It is easy to see how instructions from the 'head' to the 'feet' could be received with incredulity, and how feedback from the feet could be met with disdain. Is it possible to flourish as a profession with our 'head in the clouds' and 'feet on the ground' when it's sometimes difficult to feel like we are part of the same body? Are the realities of current practice to be navigated by clinicians alone, or the privilege and responsibility of critical thinking and the education of our practitioners to be embraced only by our scholars? Perhaps these juxtapositions affirm more than anything, the importance of bridging disconnect rather than comparing.

A study in which Australian occupational therapy hospitalbased clinicians participated in monthly discussion groups around occupational science topics, elicited a similar perceived disjunction between the experience of scholars and clinicians. They dubbed the distance, or "dissonance" between the 'head in the cloud' and 'boots in the mud' as, "utopian visions" and "dystopian realities" 32. Some participants' viewed the human rights and occupational justice principles with which they were engaging as being "too far removed from the realities of occupational therapy practice" $32: 9$. However, their prolonged engagement with occupational science principles in a collegial space, promoted ways of thinking about practice that participants had previously "rendered to an academic domain" $32: 10$. Rather than seeing a divide between "the ideals of university therapists versus the practices of hospital therapists" $32: 10 \mathrm{a}$ participant reported beginning to see opportunities for occupational justice in practice.

This account suggests that the distance between the "head" and "boots" (feet) does not necessarily need to be a barrier. Might the head and feet being able to access different aspects of people's contexts create opportunity for a fuller perspective? Might our different skills in "sensing" and "responding" be just what is required for our professional body to exercise a synergistic strength in response to our country's call for transformation? We propose that an effort to leave no one behind will strengthen the contribution that we are able to make and we propose some "do-able" directions for action to support a "whole-body" response.

\section{Recommendations: Becoming a contextually responsive academy}

Numerous priority actions have been identified that are essential to the transformation of the South African occupational therapy academy. Diversifying the academy is critical ${ }^{33}$ and university curricula need to facilitate this and be shaped by diversity. Pursuing epistemic freedom by humbly interrogating the ways that we 'think, speak and do', and collectively imagining new narratives, is vital to this ${ }^{34}$. Collective pursuit of the newly articulated Occupational Therapy research priorities for South Africa is another critical action. These priorities, and means to pursuing them, warrant robust discussion beyond the scope of this contribution. Here we would like to highlight just three recommendations that speak specifically to how we, as scholars and clinicians, might navigate the journey of becoming contextually responsive together.

\section{Context lenses: developing our ability to intervene at an environmental level}

Echoing Mary Law's perennial recommendation, we need to focus on the environment ${ }^{29}$. Theory has equipped us to look at the environment, but we struggle to see the complex environmental influ- ences that shape occupation and perpetuate occupational injustice. Our profession's scales have long tipped in favour of intervention that targets the person ${ }^{29}$, often removed from his/her context, resulting in low or unsustainable impacts. Intentionally equipping ourselves for environmental intervention is not proposed as an alternative to this, but rather a means to bringing balance and increasing our impact ${ }^{29}$. Our students should be taught how to analyse clients' occupational participation (individual and collective) in their context using frameworks that create sharp lenses for identifying the transaction between human occupation and the environment. Our undergraduate research students could generate valuable knowledge around the occupations of South African populations by analysing this participation through a lens of the social determinants of health. Additionally, undertaking such analysis in collaboration with clients or research participants will support the development of participatory behaviours and approaches. Continuous professional development opportunities can facilitate similar activities for practicing clinicians where contemporary occupation-focused conceptual frameworks are used as tools to evaluate practice and collaboratively generate visions for wider impact. We need to find ways of funding posts that target environmental change and proliferate the evidence for the invaluable role of occupational therapy across sectors for achieving national development goals ${ }^{35,36}$

\section{Communities of Praxis}

Communities of practice (CoP) have become useful vehicles for growth and development through regular engagement with others. Regular constructive engagement between our professions 'head' and 'feet' is essential if we are to build trusting partnerships that can weather the transformation journey that is inevitably both uncomfortable and exciting. A community of praxis, or CoP that focuses on the development of praxis, is proposed as a vehicle to facilitate the productive collision of reality and possibility. This would involve a small group of clinicians and scholars meeting on a monthly basis to collaboratively reflect on their practice, engage with contemporary theory, and pilot actions that are responsive to both. This cycle of theory, action and reflection holds promise for developing critical reflexivity. Through facilitation, potential exists within such groups to develop a participatory posture or where clients are partners in identifying intervention priorities and actions. Some evidence exists to suggest that communities of practice with an occupational justice and human rights focus can increase therapist's awareness of human and occupational rights and equip them for action ${ }^{12}$. This vehicle could also be used to engage with emerging practice areas and include clients and stakeholders from diverse sectors. Inclusion of Community Service occupational therapists in these groups also holds potential for meeting some of the crucial support needs of these therapists while at the same time reinforcing strategic positioning of the services that they are developing. The imminent implementation of revised CPD guidelines with a focus on demonstrating learning invites us to explore new mechanisms for our profession's growth and transformation. Accrediting learning through a CoP also incentivises participation.

\section{Rising to a 'just-right' challenge: acting as part of the whole}

Uniting in pursuit of contextual responsiveness will synergise our impact and challenging one another will sharpen our individual contributions to the whole. But as we engage one another, we propose that we need to be cognisant of facilitating a "just-right" challenge that calls for both action and caution by our 'head' and 
'feet'. An environmental challenge or press that is overwhelming will lead one to surviving the growth opportunity, rather than experiencing $i^{29}$. Excessive force, inappropriate methods, apathy or indifference will stunt the transformation process. We need to challenge one another with the view to strengthening the whole. This will require that we:

- Assume a critical posture and humble disposition: to be contextually responsive means to be critical - critical of dominant discourses or socially prevalent ideas; critical of taken-forgranted norms and assumptions. For the profession to benefit optimally from this individual and collective posture of inquiry, confrontation that is regardful is required. While exercising wisdom that does not entertain apathy or allow injustice to be perpetuated, acting in the power of humility is essential as we confront each other's assumptions and beliefs. We should assume that change is possible for the individual and collective and give each other opportunity and help to change. We should engage with one another based on our shared humanity and intrinsic dignity with an openness to learn and be challenged.

- Seek to understand each other's lived experience and intersubjectivities: It is easy to judge a pair of boots that you have never walked in. Living in each other's reality enables us to feel the fatigue of walking through resistant mud or experiencing freedom from muddy constraints that allows for renewed perspective and possibility. CPD accredited therapist exchange programmes may offer a simple way of facilitating learning and conceptualising practice beyond our own comfort zone (eg. emerging practice settings, rural community-based rehabilitation, community service placements). Experiencing each other's practice while engaging reflectively with theory will not only facilitate personal growth but will build the trust and nonjudgementalism that is required to enable collective growth.

- Pursue epistemic freedom by recognising everyone as a legitimate carrier of knowledge ${ }^{37}$ : Our knowledge creation should be accessible to all and we should avoid alienating parts of our professional body with inaccessible terminology or unexplained concepts. All contributions should be authentically acknowledged. We should interrogate our local ideological divides and guard against intellectual superiority or intellectual ethnocentrism.

- Befriend discomfort: transformation is a disruptive process, and we should be prepared for the discomfort it will bring. This will require us to open ourselves to desensitization and lower our defences that make it difficult to see things from a different angle. We should acknowledge that transformation is a process, that we will not always have the answers and that there will be periods of 'getting stuck'.

- Be careful of serving efficiency over justice: Buttressed by neoliberalism's hyper-norm of subsuming economic market values (i.e. valuing that which can be counted and gained for person benefit) into all spheres of life ${ }^{23}$, our working environments typically reward, or fiercely demand, productivity. We thus have to be mindful of creating time and space for critical reflection in our practice. Instead of doing more, we should attend to what really matters and position our labour for addressing injustice or responding to professional priorities strategically rather than feverishly.

\section{CONCLUSION}

Is contextual responsiveness a process, a product, a posture, or a description of transformation? We would propose that it is all of these. If these reflections have left you with more questions than answers, we ask that you keep asking them with us as we interrogate what this means for our practice, policy, education and life-long learning, and our research. Contextual responsiveness is an imperative pursuit - a journey that we must take - a journey we must take together. What is there to be gained, you may ask? Impact. Justice. Change. Being part of the living, breathing and beating heart of a profession.

\section{AUTHOR CONTRIBUTIONS}

Kirsty van Stormbroek the arguments posed in this commentary in commentary and wrote the first draft. Tania Rauch van der Merwe reviewed, commented on and refined the manuscript. Both authors reviewed and edited the manuscript (and approved the final version of the manuscript). Both authors agree to be held accountable for all aspects of the work.

\section{REFERENCES}

I. Yerxa EJ. 1966 Eleanor Clarke Slagle lecture: Authentic occupational therapy. The American journal of occupational therapy: official publication of the American Occupational Therapy Association, 1967;2I(I): I-9.

2. Aristotle. The Nicomachean ethics. New York: Oxford University Press; 1998.

3. Department of Health (DOH). Ethics in Health Research: Principles, Processes and Structures. [Online] 2015. Available from:

https://www.sun.ac.za/english/research-innovation/ResearchDevelopment/Documents/Integrity and Ethics/DoH 2015 Ethics in Health Research - Principles, Processes and Structures 2nd Ed.pdf

4. Joubert R. Exploring the history of occupational therapy's development in South Africa to reveal the flaws in our knowledge base. South African Journal of Occupational Therapy. [Online] 20 I0;40(3): 21-26. Available from:

http://www.scielo.org.za/pdf/sajot/v40n3/06.pdf

5. Hammel KRW. Client-centred occupational therapy: the importance of critical perspectives. Scandinavian Journal of Occupational Therapy. [Online] 2015;22: 237-243. Available from: doi:https://doi.org//0.3109//1038128.2015.1004103

6. Ramugondo E, Kronenberg F. Explaining Collective Occupations from a Human Relations Perspective: Bridging the IndividualCollective Dichotomy. Journal of Occupational Science. [Online] 20I5;2I(I): 3-16. Available from: doi:http://dx.doi.org/10.1080/14427591.2013.781920

7. Coovadia H, Jewkes R, Barron P, Sanders D, Mclntyre D. The health and health system of South Africa: historical roots of current public health challenges. Lancet. [Online] Elsevier Ltd; 2009;374(9692): 817-834. Available from: doi:I0.1016/S0I40-6736(09)6095I-X [Accessed: 22nd January 2014]

8. Bloom G, Mclntyre D. Towards equity in health in an unequal society. Social science \& medicine (1982). [Online] 1998;47(10): 1529-1538. Available from: https://pubmed.ncbi.nlm.nih.gov/9823048/

9. African National Congress. National Health Plan for South Africa. [Online] Available from: http://www.anc.org.za/show.php?id=257

10. Harrison D. An Overview of Health and Health care in South Africa $1994-2010$ : Priorities, Progress and Prospects for New Gains. [Online] 2009. Available from: https://www.health-e.org.za/wp-content/uploads/2013/05/3f9|42 5a05dffe9e I 2 I 74b7c2ff0db4d I.pdf

11. The Health Professions Council of South Africa. Report on the demographics of registered occupational therapists. Pretoria; 2019.

12. National Department of Health. Human Resource Number as at I 
February 2018. 2018.

13. Statistics South Africa. General Household Survey 2018 - Statistical Release PO318. General Household Survey 2018. [Online] 2018;(May): 203. Available from:

http://www.statssa.gov.zainfo@statssa.gov.za

14. Iwama MK, Thomson NA, MacDonald RM. The Kawa model: The power of culturally responsive occupational therapy. Disability and Rehabilitation. [Online] 2009;3 I(I4): II25-II35. Available from: doi: I0.1080/096382809027737। I

15. Law M, Cooper B, Strong S, Stewart D, Rigby P, Letts L. The Person-Environment-Occupation Model: $A$ transactive approach to occupational performance. Canadian Journal of Occupational Therapy. [Online] 1996;63(I): 9-23. Available from: doi: 10.11 777/000841749606300103

16. Dunn W, Brown C, McGuigan A. The ecology of human performance: a framework for considering the effect of context. The American journal of occupational therapy. : official publication of the American Occupational Therapy Association. [Online] 1994;48(7): 595-607. Available from: doi: 10.50 I4/ajot.48.7.595

17. Polatajko H, Townsend E, Craik J. Canadian model of occupational performance. In: Polatajko E, Townsend $\mathrm{H}$ (eds.) Enabling occupation II: Advancing an occupational therapy vision for health, wellbeing, \& justice through occupation. Ottawa, ON: CAOT Publications ACE; 2007. p. 22-36.

18. Fisher A G, Marterella A. Powerful Practice: Planning and Implementing Authentic Occupational Therapy Services. [Online] Powerful Practice: A model for authentic occupational therapy. Fort Collins: CO: Centre for Innovative OT Solutions; 2019. Available from: https://www.innovativeotsolutions.com/wp-content/ uploads/2019/03/I-3-day-Powerful-Practice-Course-Overview.pdf

19. World Health Organization. Social determinants of health. [Online] Health Topics. file://localhost/Available from/ https/::www.who.int:health-topics:social-determinants-of-health - tab =tab_I [Accessed: 20th August 202I]

20. Whiteford G, Jones K, Rahal C, Suleman A. The Participatory Occupational Justice Framework as a tool for change: Three contrasting case narratives. Journal of Occupational Science. [Online] Taylor \& Francis; 2018;25(4): 497-508. Available from: doi: 10.1080/1442759I.2018.1504607

21. Galvaan R, Peters L. Occupation-based community development: Confronting the politics of occupation. In: Sakellariou D, Pollard $\mathrm{N}$ (eds.) Occupational Therapies without Borders: Integrating justice with practice. 2nd Editio. United Kigdom: Elsevier; 2017. p. 283-29l.

22. Wilcock A. An Occupational Perspective of Health.2nd Editio. Thorofare: SLACK Incorporated; 2006.

23. Brown W. Undoing the Demos: Neoliberalism's Stealth Revolution. The European Legacy. New York: Zone Books; 2015.

24. Sebake B. Neoliberalism in the South African Post-Apartheid Regime: Economic Policy Positions and Globalisation Impact. The 2nd Annual International Conference on Public Administration and Development Alternatives.

25. Galvaan R. The contextually situated nature of occupational choice: Marginalised young adolescents' experiences in South Africa. Journal of Occupational Science. [Online] Taylor \& Francis; 2015;22(I): 39-53. Available from: doi: 10.1080/I442759I.2014.912124

26. Richards L, Galvaan R. Developing a socially transformative focus in Occupational Therapy: insights from South African practice. South Africa Journal of Occupational Therapy. [Online] 20I8;48(I): 3-8. Available from:

doi:http://dx.doi.org/I0.17159/2310-3833/2017/vol48nla2
27. NIH National Cancer Institute. Body functions and life process. [Online] Available from:

https://training.seer.cancer.gov/anatomy/body/functions.html [Accessed: 20th August 2021]

28. Ramugondo EL. Occupational Consciousness. Journal of Occupational Science. [Online] Taylor \& Francis; 20I5;22(4): 488-50I. Available from: doi: 10.1080/1442759I.2015.1042516

29. Law M. The environment: a focus for occupational therapy (1991 Muriel Driver Lecture). Canadian Journal of Occupational Therapy. Revue canadienne d'ergothérapie. [Online] 199|;58(4): |7|-|79. Available from: doi:https://doi.org//0.1 I77/00084I749/05800404

30. Owens $L$. Our professional existence is political: Critical reflections on 'seeing white' in occupational therapy. In: Sakellarious N, Pollard $\mathrm{N}$ (eds.) Occupational Therapies without Borders. London: Elsevier Ltd; 2017.

31. Karran T. Academic freedom: In justification of a universal ideal. Studies in Higher Education. [Online] 2009;34(3): 263-283. Available from: doi: 10.1080/03075070802597036

32. Galvin D, Wilding C, Whiteford G. Utopian visions/dystopian realities: Exploring practice and taking action to enable human rights and occupational justice in a hospital context. Australian Occupational Therapy Journal. [Online] 201 I;58(5): 378-385. Available from: doi: I0.1 I I I/j. I440-1630.201।.00967.x

33. Ned L, Tiwari R, Buchanan H, Van Niekerk L, Sherry K, Chikte U. Changing demographic trends among South African occupational therapists: 2002 to 2018. Human Resources for Health. [Online] Human Resources for Health; 2020;18(I): 1-12. Available from: doi: I0.I I86/s I2960-020-0464-3

34. Rauch van der Merwe T. The political construction of occupational therapy in South Africa: Critical analysis of a curriculum as discourse. [Online] University of the Free State; 2020. Available from: http:// hdl.handle.net/I 1660/10424

35. Department of Health. National Health Insurance for South Africa:towards universal health coverage. [Online] 2015. Available from: https://www.mm3admin.co.za/documents/docmanager/ f447b607-3c8f-4eb7-8da4-I l bca747079f/00090702.pdf

36. National Planning Commission, Department of the Presidency $R$ of SA. National Development Plan -2030. [Online] 2012. Available from: https://www.gov.za/sites/default/files/gcis_document/201409/ ndp-2030-our-future-make-it-workr.pdf

37. Fricker M. Epistemic injustice. Power and the Ethics of Knowing. Oxford: Oxford University Press; 2007.

Corresponding Author

*Kirsty van Stormbroek

Email: kirsty.vanstormbroek@wits.ac.za 